\title{
Association between inter-organizational consensus on use of research evidence and stage of implementation of an evidence-based practice
}

\author{
Lawrence A Palinkas ${ }^{*}$, C Hendricks Brown ${ }^{2}$, Lisa Saldana ${ }^{3}$, Patricia Chamberlain ${ }^{3}$ \\ From 7th Annual Conference on the Science of Dissemination and Implementation in Health \\ North Bethesda, MD, USA. 8-9 December 2014
}

\begin{abstract}
Introduction
Two critical but poorly understood components of EBP implementation requiring collaboration across different organizations are interactions among key stakeholders and use of research evidence (URE). This paper examines the association between consensus on URE among leaders of different child-serving systems and stage of implementation of an evidence-based practice.
\end{abstract}

\section{Methods}

Information on research evidence acquisition, evaluation and application were collected from 140 directors and senior administrators of child welfare, mental health and juvenile justice systems in 40 California and 11 Ohio counties participating in an RCT of the use of community development teams to scale up implementation of Multidimensional Treatment Foster Care over a 3 year period (2010-12). Individual data were grouped into 44 clusters, defined as 3 or more participants from 2 or more organizations in a county in a specific year. We used two separate methods for calculating consensus, cultural consensus analysis [1] of responses to the Structured Interview of Evidence Use [2], and SEM of average SIEU scale and subscale scores [3,4]. Mixed effects models were used to estimate associations between individual and group measures of URE and Stage of Implementation Completion [5] scores.

\section{Findings}

Stage of implementation (maximum stage achieved and time to completion) was significantly associated with both measures of consensus on research evaluation $(r=0.42$

'Department of Children, Youth and Families, School of Social Work,

University of Southern California, Los Angeles, CA 90089-0411, USA

Full list of author information is available at the end of the article $\mathrm{p}=0.015)$, application $(\mathrm{r}=0.47 \mathrm{p}=0.006)$, and engagement in overall URE $(r=0.40 \mathrm{p}=0.022)$, independent of state and year.

\section{Relevance to D\&I}

Cultural consensus measures of URE may serve two purposes for implementation science: 1) a measure of inter-organizational culture, comprised of extent of shared understandings of URE, and 2) a predictor of stage of EBP implementation that requires collaboration between multiple organizations.

\section{Funding}

National Institute of Mental Health (R01MH076158), and the William T. Grant Foundation (\#10648).

\section{Authors' details}

'Department of Children, Youth and Families, School of Social Work, University of Southern California, Los Angeles, CA 90089-0411, USA. ${ }^{2}$ Department of Psychiatry and Behavioral Sciences, Feinberg School of Medicine, Northwestern University, Chicago, IL 60657, USA. ${ }^{3}$ Oregon Social Learning Center, Eugene, OR 97401, USA.

Published: 20 August 2015

\section{References}

1. Romney AK, Weller SC, Batchekler WH: Culture as consensus: a theory of culture as information accuracy. American Anthropologist 1986, 88(2):313-338.

2. Palinkas LA, Garcia AR, Aarons GA, Finno-Velasquez M, Holloway IW, Mackie T, Leslie LK, Chamberlain P: Measuring use of research evidence in child-serving systems: The Structured Interview for Evidence Use (SIEU). Research on Social Work Practice 2014, Dec 1., epub ahead of print.

3. Chan D: Functional relations among constructs in the same content domain at different level of analysis: A typology of composition models. Journal of Applied Psychology 1998, 83(2):234-246.

4. Raudenbush SW, Martinez A, Bloom H, Zhu P, Lin F: An eight-step paradigm for studying the reliability of group-level measures, Report from the William T. Grant Foundation. 
5. Chamberlain $\mathrm{P}$, Brown $\mathrm{CH}$, Saldana L: Observational measure of implementation progress in community-based settings. The Stages of Implementation Completion (SIC). Implementation Science 2011, 6:116.

doi:10.1186/1748-5908-10-S1-A20

Cite this article as: Palinkas et al:: Association between inter-

organizational consensus on use of research evidence and stage of implementation of an evidence-based practice. Implementation Science 2015 10(Suppl 1):A20

Submit your next manuscript to BioMed Central and take full advantage of:

- Convenient online submission

- Thorough peer review

- No space constraints or color figure charges

- Immediate publication on acceptance

- Inclusion in PubMed, CAS, Scopus and Google Scholar

- Research which is freely available for redistribution

Submit your manuscript at www.biomedcentral.com/submit 